\title{
RESPONSABILIDAD PENAL DE LAS PERSONAS JURÍDICAS CON ESPECIAL REFERENCIA AL DECRETO 130-2017 QUE CONTIENE EL NUEVO CÓDIGO PENAL DE HONDURAS
}

\section{Autor: Raúl Gilberto Rivas Paniagua ${ }^{1}$}

DOI: https://doi.org/10.5377/Ird.v41i1.10486

\section{RESUMEN:}

En este artículo se hace un análisis de lo que corresponde a la responsabilidad penal de las personas jurídicas en el nuevo Código Penal, se plantea cual es el modelo de responsabilidad penal que sigue el mismo, el cual, es un modelo que ha fracasado y poco sostenido por la Dogmática y por la jurisprudencia. De igual manera, se plantea quienes son las personas jurídicas que responden penalmente, así como las que no responden. Se hace un análisis de las sanciones aplicables a las empresas, que en cierta manera entran en choque con las sanciones administrativas porque las mismas sanciones penales aplicables a la empresa también se pueden aplicar desde la perspectiva del Derecho Administrativo sancionador, aunque esto último con cierto rechazo, la doctrina no se pone de acuerdo todavía, si son penas, o si son sanciones administrativas.

\section{PALABRAS CLAVE:}

Responsabilidad penal, Derecho penal de empresas, modelo de imputación penal a empresas, sanciones penales.

1 Abogado por la UNAH/Master en Derecho Penal por la Universidad de Sevilla, España/ Curso de Experto en Delitos Patrimoniales, Económicos y de la Empresa por la Universidad Autónoma de Madrid, España.

Corro Elecrónico: paniagua_raul@yahoo.es 


\title{
CRIMINAL LIABILITY OF LEGAL PERSONS WITH SPECIAL REFERENCE TO DECREE 130-2017 CONTAINING THE NEW HONDURAS CRIMINAL CODE
}

\section{Raúl Gilberto Rivas Paniagua²}

\section{DOI: https://doi.org/10.5377//rd.v41i1.10486}

\begin{abstract}
ABSTRAC:
In this article, an analysis is made of what corresponds to the criminal responsibility of legal persons in the new Criminal Code, and the model of criminal responsibility that it follows is proposed. Likewise, it raises who are the legal persons that respond criminally, as well as the legal persons that do not respond. An analysis is made of the sanctions applicable to companies, which in a certain way clash with administrative sanctions because the same criminal sanctions to the company can also be applied from the perspective of the sanctioning Administrative Law, although the latter is somewhat rejected, the doctrine still does not agree, if they are penalties, if they are administrative sanctions.
\end{abstract}

KEYWORDS: Criminal responsibility, criminal law of companies, model of criminal imputation to companies, criminal sanctions.

Date received: August 11, 2020

Approval date: October 12, 2020

2 Lawyer from the UNAH / Master in Criminal Law from the University of Seville, Spain / Expert Course on Patrimonial, Economic and Business Crimes from the Autonomous University of Madrid, Spain.

Email: paniaguaraul@yahoo.es. 


\section{INTRODUCCION}

El 25 de junio de 2020 entro en vigencia el Nuevo Código Penal que contiene el DecretoLegislativo 130-2017 que es el Certificado de nacimiento del nuevo Código Penal y es el acta de defunción del Decreto 144-83 antiguo Código Penal (ver articulo 634 y 635 nuevo $\mathrm{CP}$ ), tal normativa, para unos entro en vigencia, para otros no. En mi opinión, no entro en vigencia, por lo que señala el artículo 188 párrafo segundo de la Constitución de la Republica (sobre la CR no se sobrepone ninguna normativa infra-constitucional), en vista de que tal artículo no da lugar a una interpretación abierta, sino absolutamente cerrada, aunque dicha reforma sobre el artículo 635 de este nuevo Código Penal haya sido decretada antes de la suspensión de los Derechos Constitucionales por el COVID-19.

No debemos olvidar que un decreto legislativo ni un Código Penal ni cualquier Ley está por sobre la Constitución de la Republica, algunos constitucionalistas olvidan que todo lo que entra en colisión con la Constitución de la Republica, se aplica esta última por el principio de jerarquía normativa. El presente Código en análisis, ha sido rechazado por una gran mayoría de la sociedad en general y por un grupo importante de la Sociedad Civil, y no es para menos, quienes lo aprobaron no están legitimados para ello, en vista de que son personas acusadas con amplios vínculos de narcotráfico y de redes de corrupción, y en ese mismo sentido, no era momento para que fuese aprobado y que entre en vigencia. No sería objetivo este análisis, si no se expresa que el mismo, dogmática y normativamente es de vanguardia, así que, desde la parte general, contiene los principios políticocriminales bien definidos, cuestión que no la tenía el Código Penal derogado, contiene bien detallado el tema de la tentativa, como el error, y el tema concursal, entre otros puntos.

Desde la parte especial, hay tipos penales de actualidad, si bien es cierto, que el mismo ha sido criticado por contemplar bajas penas privativas de libertad, desde la teoría de la pena, sin duda alguna, que se le dado importancia a la multa y al tema de las inhabilitaciones, no cabe duda que la pena de prisión es la que intimida a los delincuentes de cuello blanco, tal pena de prisión no intimida a los delincuentes comunes, es lo de menos para ellos.

Una novedad que marca este Código Penal, es la responsabilidad penal de las personas jurídicas. Es un tema novedoso, pero criticado por un sector importante de la doctrina, aunque cada día que pasa se van sumando más seguidores sobre este nuevo sujeto responsable penalmente. $\mathrm{Si}$ bien es cierto, por cabildeos de la empresa privada, tal responsabilidad ha sido derogada bajo el Decreto-Legislativo de fecha 5 de noviembre de 2019, lo cual, a esta fecha 28 de julio 2020 tal Decreto de la derogatoria no ha sido publicado en la Gaceta, al parecer se va hacer una sola derogatoria de varios artículos del nuevo Código Penal. Esto da a entender que, si no hay publicación en el Diario Oficial La Gaceta, pues la responsabilidad penal de la persona jurídica está vigente, aunque sea por unos meses, pero estuvo vigente, seguramente cuando este articulo vea la luz ya estará derogada. 
La irrupción de esta sistemática lo marco la globalización, vino a trastocar las figuras dogmáticas de lo que se denomina un derecho penal clásico o nuclear. El concepto de los bienes jurídico tampoco se salvó de ser trastocado, en vista de que se habla de bienes jurídicos supraindividuales, y que estos son distintos a los bienes jurídicos del derecho penal nuclear, que son generalmente delitos de lesión, con un resultado concreto, y los bienes jurídicos supraindividuales, la victima suele ser la colectividad. El estudio de tal responsabilidad responde a dar a conocer los problemas que presenta la misma, lo cual, el tema desde una perspectiva de la política criminal si se puede mantener, pero desde un punto de vista dogmático no. La barrera o el dique de la política criminal es la Dogmática jurídico penal.

En el presente artículo, se desarrollará desde una perspectiva normativa, así como está establecida en el nuevo Código Penal la responsabilidad penal de las personas jurídica haciendo una relación dogmática entre ambos elementos, con el objetivo de enriquecer el análisis. El artículo 102 de Código Penal vigente, regula la mencionada responsabilidad penal de la persona jurídica, teniendo una serie de parámetros en las cuales se enmarca la misma. Debe quedar claro que no existe responsabilidad penal de las sociedades mercantiles, si la misma, no se lleva a cabo a través de una persona física, pero esta persona, debe actuar de manera que su actuación beneficie a la persona jurídica, sino la beneficia, no responde penalmente la empresa.
El entramado empresarial, funciona de una manera organizativa, donde se conjuga la actuación de una serie de personas, las cuales cada una de ellas, tiene su propia responsabilidad penal de acuerdo a su competencia en las actividades empresariales, pero el hecho de que se haya cometido un delito empresarial, y no se pueda identificar a la persona natural, no quiere decir que no se le puede imputar un delito a la empresa. Este Código excluye de responsabilidad penal al Estado como persona jurídica, en algunas legislaciones puede responder el Estado cuando una entidad pública desarrolla actividades conjuntamente con una sociedad mercantil privada, únicamente podrá responder el Estado cuando el delito vaya referido a delitos cometidos contra la seguridad social. También se determinan una serie de penas aplicables a las personas jurídica, lo cual, la pena de multa, es la pena principal en los delitos de empresa, aparejada a la multa, se pueden sumar otras, que el Código las denomina penas potestativas, que quedaran a discreción del Juez si las impone, la generosidad de este código lleva a que sobre el mismo se determinen una serie de circunstancias atenuantes que una vez se descubra el delito y se impute, la empresa puede optar a ellas, lo que si no se determina concretamente, cual es el grado de atenuación de la pena, asimismo, se establecen 5 numerales de causas que suspenden el proceso penal a la empresa, el cual, tal responsabilidad, quedara condicionada a una o varias condiciones que impondrá el juez de acuerdo a sus valoraciones. 


\section{METODOLOGIA}

El tema objeto de estudio se plantea desde el punto de vista teórico, analítico-descriptivo, planteando la problemática de incluir en un Código Penal, una responsabilidad, que, hasta este momento, ha irrespetado los más elementales principios del Derecho Penal, en el mismo sentido, este análisis se hace acompañado de los análisis de la Dogmática más excelsa del Derecho Penal Económico, vinculando los mismos, con el Derecho positivo que acarrea el nuevo Código Penal en los distintos artículos de la Parte General.

\section{PERSONAS JURIDICAS PENALMENTE RESPONSABLES}

En el Decreto-Legislativo 130-2017 que da nacimiento al nuevo Código Penal, se establece la responsabilidad penal de la empresa en los artículos 102, 103, 104 y 105, estos artículos son la base para deducir responsabilidad penal a las personas jurídicas, es decir, que esta es la Parte General aplicable a todos los delitos concretos de la parte especial. Inicialmente como derecho positivo se concreta aquí este modelo de responsabilidad en Honduras donde se asientan los cimientos de la responsabilidad penal de las sociedades mercantiles, de esta manera se abandona el societas delinquere non potest. Son necesarias algunas reflexiones sobre ello, no podemos obviar que en algún momento determinado de lege ferenda haya que retomar la discusión en el Parlamento sobre su aprobación. En un sentido realista, Honduras no está preparada para este tipo de responsabilidad.
Las críticas a este sector de responsabilidad no se han hecho esperar, se han lanzado certeras críticas sobre la misma. Desde la perspectiva política-criminal se ha dicho que es necesaria la modernización del Derecho Penal, porque el modelo de Derecho Penal que ha dominado la Dogmática Penal no resuelve los problemas sociales en la sociedad ${ }^{3}$, también se ha dicho que este Derecho Penal clásico resulta ineficaz, de igual forma, hay que adaptar el Derecho penal a los instrumentos internacionales que recomiendan sancionar a las empresas

En términos generales, se ha planteado que la responsabilidad penal es sobre la base de actuación de una persona física, una persona que piensa, que ejecuta acciones voluntariamente y tiene la capacidad mental de determinar qué acciones son relevantes o irrelevantes para el Derecho Penal, y esos elementos solo ocurren en la persona física, expreso en un congreso virtual el Prof. Dr. Fernando Molina Fernández, que la persona jurídica siempre esta inconsciente.

Este modelo de responsabilidad penal, está determinada para sociedades mercantiles de orden privado, no para empresas públicas en su totalidad, puede haber empresas en alianza publica-privadas que a ellas si se les puede imputar delitos empresariales, para ello, es preciso analizar el artículo 102 del nuevo Código Penal, que determina quienes son las personas jurídicas penalmente responsables, inter alía, tal artículo señala lo siguiente:

3 Bacigalupo, S. (2002) La responsabilidad penal de las personas jurídicas: Un problema del sujeto del Derecho penal. En: Mir Puig, S., Modolell Gonzales, J.L., Gallego Soler, J-I., Bello Rengifo, C.S., Estudios de Derecho Penal Económico (152-182) Venezuela. Livrosca. 
ARTICULO 102. En los supuestos previstos en el presente Código, las personas jurídicas son penalmente responsables de los delitos dolosos cometidos en nombre o por cuenta de las mismas y en su beneficio, por sus representantes legales o administradores de hecho o de derecho.

La concurrencia, en las personas que materialmente hayan realizado los hechos, de circunstancias que afecten a la culpabilidad del acusado o agraven su responsabilidad o, el hecho de que dichas personas hayan fallecido o se hubieren sustraído a la acción de la justicia, no excluirá ni modificara la responsabilidad penal de las personas jurídicas, sin perjuicio de lo que se dispone en el Articulo siguiente. Del mismo modo, aunque la persona jurídica deje de existir antes de recaer sentencia firme, no excluirá la responsabilidad penal de las personas naturales.

La responsabilidad penal de las personas naturales es independiente de la que corresponda a las personas jurídicas, pero en relación con las penas pecuniarias si por el tamaño de la persona jurídica la acumulación de ambas resultara desproporcionada, el Órgano Jurisdiccional competente modulara las mismas para evitar la desproporción del castigo ${ }^{4}$

Para analizar el presente artículo, debemos desglosarlo por partes. En primer lugar, la responsabilidad penal en un Estado de Derecho, es personal, es propia de la persona que cometió el injusto penal, y no responde por un hecho ajeno de otra persona ${ }^{5}$, no se le puede determinar delito a quien no lo ha cometido, esa es la esencia del Derecho Penal Democrático.

El Código Penal establece que las personas jurídicas son las responsables de los delitos

4 Decreto-Legislativo 130-2017. Código Penal de Honduras. 5 Pérez Manzano, M. (2019) "Principios del Derecho Penal (III)”. En Manual de Introducción al Derecho Penal, (91-117) Madrid, BOE. dolosos que cometan sus administradores de hecho o de derecho, aquí, en este apartado podemos ver el quebrantamiento del principio anteriormente descrito implícitamente, que la responsabilidad penal del hecho es personal, es decir, que no se puede transferir el delito a otra persona que no posee dolo ni imprudencia. Claramente se determina la transferencia de la responsabilidad penal de la persona física, (que, en este caso, son los administradores de hecho y de derecho) a la persona jurídica, esto representa una transferencia o un modelo de responsabilidad penal inaceptable desde el punto de vista de los principios del Derecho Penal, es así, que, siguiendo un modelo tradicional de imputación, no se puede penar a quien no ha cometido delito y aquí se pena a la persona jurídica que no ha cometido delito.

Sobre la base de lo anteriormente descrito, se presenta como modelo de imputación de la empresa, el modelo de heterorresponsabilidad, que es el modelo que presenta el artículo 102 de este Código Penal nuevo, un modelo que transfiere la responsabilidad penal de persona física a la persona jurídica ${ }^{6}$, es un modelo que no ha tenido éxito, que representa un modelo de responsabilidad objetiva. Es necesario hacer una referencia sucinta a lo siguiente, en primer término, en Derecho Español, la Ley Orgánica 5/2010, de 22 de junio, introdujo la responsabilidad penal de las personas jurídicas en España, introduciendo como modelo de responsabilidad penal el

6 Paniagua, R. (2017). Fundamentos de la Responsabilidad Penal de la Empresa como nuevo sujeto activo del delito. Revista de Derecho, Volumen 38, № 1, 20, 15-24. En el mismo sentido, Silva Sánchez, J.M. (2013) La responsabilidad penal de las personas jurídicas en Derecho Español. En Silva Sánchez J.M. Dir., Montaner Fernández, R., Coord. "Criminalidad de Empresas y Compliance" Prevención y reacciones corporativas. (15-42) Barcelona. Atelier. 
modelo anteriormente descrito que contenía, un modelo de transferencia, a tal modelo se le plantearon una serie de críticas bastante contundentes, que obligó al legislador español a reformar el Código Penal español mediante la LO 1/2015, de 30 de marzo $^{7}$, introduciendo o pretendiendo introducir un nuevo modelo de responsabilidad penal, el cual, este modelo de autorresponsabilidad, no lo contempla el Decreto 130-2017.

Al parecer, si se hubiese aprobado en Honduras la RPPJ, hubiésemos seguido el mismo camino que en España, que primero se aprobó el modelo de responsabilidad penal más problemático y después mediante una reforma se aprueban los modelos de prevención y gestión dando vida a la autorresponsabilidad, aunque a criterio de un sector doctrinal se maneja que España sigue un modelo mixto de responsabilidad penal de la persona jurídica, luego el Congreso Nacional hubiese tenido que reformar el Código Penal introduciendo un nuevo modelo de responsabilidad penal porque el anterior violentaba el principio de

7 Boletín Oficial del Estado. https://www.boe.es/buscar/act. php?id=BOE-A-2015-3439. Consultada en fecha 9 de julio 2020. La reforma lleva a cabo una mejora técnica en la regulación de la responsabilidad penal de las personas jurídicas, introducida en nuestro ordenamiento jurídico por la Ley Orgánica 5/2010, de 22 de junio, con la finalidad de delimitar adecuadamente el contenido del «debido control», cuyo quebrantamiento permite fundamentar su responsabilidad penal. Con ello se pone fin a las dudas interpretativas que había planteado la anterior regulación, que desde algunos sectores había sido interpretada como un régimen de responsabilidad vicarial, $\mathrm{y}$ se asumen ciertas recomendaciones que en ese sentido habían sido realizadas por algunas organizaciones internacionales. En todo caso, el alcance de las obligaciones que conlleva ese deber de control se condiciona, de modo general, a las dimensiones de la persona jurídica. Asimismo, se extiende el régimen de responsabilidad penal a las sociedades mercantiles estatales que ejecuten políticas públicas o presten servicios de interés económico general, a las que se podrán imponer las sanciones actualmente previstas en las letras a) y g) del apartado 7 del artículo 33 del Código Penal. culpabilidad, entre otros, la cuestión era en aquel momento, porque no haber tomado el ejemplo de España, para no caer en el error que tuvieron ellos.

Asimismo, el primer párrafo del artículo 102 del Código Penal en vigencia, hace referencia a que los delitos de empresa, son cometidos únicamente en la modalidad dolosa, excluyendo en este caso, la imprudencia, aunque algunos delitos de empresa también pueden ser llevados a cabo con imprudencia, como lo señala el artículo 440 del NCP sobre el delito de lavado de activos imprudente - Aquí puede sostenerse que en la dinámica empresarial también se pueden llevar a cabo errores de tipo, por algún tipo de desconocimiento, ese desconocimiento lleva al error, el error de tipo, puede ser vencible e invencible, de cualquiera de estos dos elementos, la responsabilidad penal de la empresa quedará impune ${ }^{8}$, y será por otra vía que tendrá que buscarse la responsabilidad penal de la empresa.

En la actividad empresarial lo que se busca es el lucro de la empresa, y el gobierno corporativo para eso trabaja, la responsabilidad penal de las personas jurídicas, está preparada para aquellas economías dinámicas, no para economías lentas, porque el mercado es exigente y la competencia es dura, y toda empresa quiere generar más ganancias para sí misma.

Una vez que deja de existir el principio societas delinquere non potest, se da paso 8 Ragués i Vallés, R. (2018) “Delito y Empresa”. En Ragués i Vallés, R, Robles Planas (dirs), R. La Imputación Subjetiva en los Delitos Económicos y en la Criminalidad de Empresa. (93118) Barcelona. Atelier. 
al societas delinquere potest, la empresa es un nuevo sujeto activo de la responsabilidad penal, para ello, quienes actúan al interno de la misma, deben llevar a cabo el delito a nombre y por cuenta de la empresa, porque quien actúa es la empresa a través de sus representantes legales o a través de sus administradores de hecho y de derecho, y al llevarse a cabo el delito a nombre y por cuenta de la empresa, esta se beneficia de la actividad criminal que lleva a cabo.

Aquí se entiende o se debe entender que quien está delinquiendo es la empresa, porque es ella quien actúa en la ejecución o en el desarrollo de su actividad empresarial propia para la cual fue creada, es decir, que, si se comete un delito fiscal, si se comete un delito laboral es la empresa la que delinque en el marco de sus funciones empresariales ${ }^{9}$. Queda claro lo anterior, si los representantes de la empresa, o los administradores de hecho o de derecho actúan a título personal, la empresa quedara absuelta de responsabilidad penal, en ese sentido, obviando los requisitos del 102 $\mathrm{CP}$, la empresa no responde, respondería la persona que actuó a su nombre como persona natural, no jurídica.

Hay momento en que en la actividad empresarial, empresas desarrollan actividades conjuntas, pero cada empleado de cada empresa responde por lo suyo, por los intereses de su empresa, el hecho de trabajar conjuntamente o distribuir productos de determinada marca, no quiere decir que la

9 Dopico Gómez-Aller, J. (2018) "La Responsabilidad Penal de las Personas Jurídicas”. En De la Mata Barranco, N., Dopico Gómez-Aller., J. Lascuraín Sánchez, Nieto Martin, A. Derecho Penal Económico y de la Empresa. (129-168) Madrid. Dykinson. responsabilidad es conjunta, por ejemplo, un empleado de una empresa fabricante de una marca de automóviles, no puede responder penalmente de lo que haga la agencia distribuidora a la hora de vender automóviles, pero puede ocurrir, que ese empleado fuera de la legalidad empresarial se confabule con él de la otra empresa para sacar un provecho para sus empresas, ahí podría determinarse algún tipo de responsabilidad penal ${ }^{10}$.

Comolaactividaddelictivaobligatoriamente para que responda penalmente la empresa, debe cometerse por cuenta y en nombre de la persona jurídica, es decir, que la persona física, debe actuar como persona jurídica, como empresa, si la actividad es delictiva, pues la empresa tendrá un beneficio, ese beneficio hace posicionarse a la empresa más alto que sus competidoras, y eso hace una competencia desleal, la conducta delictiva altera el correcto funcionamiento del mercado, y todo esto, genera desconfianza en el mercado, por ejemplo, genera desconfianza en los inversores.

\section{El Código Penal, únicamente hace} referencia al concepto de beneficio, que es un concepto amplio, este beneficio puede ser directo o indirecto, el hecho que sea un beneficio a la empresa, no quiere decir, que la empresa únicamente deba recibir dinero en metálico, el beneficio puede ser de distinta naturaleza, podría ser, recibir ventajas frente a competidores, ahorro de costos, beneficios de imagen corporativa, evitar investigaciones mediante soborno de un funcionario ${ }^{11}$, entre otros beneficios.

10 Feijoo Sánchez, B. (2015) “Los Requisitos del Artículo 31 bis 1”. En Bajo Fernández, M, Feijoo Sánchez, B.J., Gómez-Jara, C. Tratado de Responsabilidad Penal de las Persona Jurídica (7588) Civitas. Navarra.

11 Ibíd. 82-83. 
Continuando siempre en el artículo 102 del Código Penal, precisamente en el párrafo segundo, que hace mención a que las personas físicas que materialmente han ejecutado los hechos y que afectan y agravan la responsabilidad de la empresa, esas personas físicas, aunque desaparezcan por fallecimiento, o se hubiesen sustraído de la potestad punitiva del Estado, no excluirá la responsabilidad penal de la persona jurídica.

$\mathrm{Si}$ bien es cierto, en la criminalidad de empresa, en el delito, concurre la actuación de la persona física y la persona jurídica, la dirección de la empresa está a cargo siempre de una persona física, en la comisión del delito van a responder ambas personas, esa es la generalidad, pero sucede que en la dinámica de grupo concurren un sinnúmero de personas, que muchas veces resulta difícil identificarlas, máximo cuando a lo endógeno de la empresa hay una cultura defectuosa de organización, no hay una cultura de fidelidad al derecho, en esos escenarios resultaría mucho más difícil identificar a la persona física competente de gestionar el riesgo empresarial sobre el cual se concretó el delito empresarial, pero tenemos un delito, en ese caso, únicamente se imputara la responsabilidad penal a la empresa.

Aún, dentro de la empresa, cumpliendo todos los códigos de ética, todos los códigos de conducta, todos los programas de prevención de riesgos empresariales, si no se identifica a la persona física, el procedimiento penal de igual manera se dirigirá contra la persona jurídica $^{12}$. De la misma manera anteriormente

12 Zugaldía Espinar, J.M. (2015) España. La Responsabilidad Criminal de las Personas Jurídicas en el Derecho Español. (Análisis de la cuestión tras la reforma operada por la LO 1/2015, de 30 de marzo) En Zugaldía Espinar, J.M., Marín de Espinosa Ceballos E.B., La Responsabilidad Criminal de las personas descrita, si existe la comisión de un delito, y la persona fallece, o se sustrae la persona física, siempre se va a imputar a la empresa el delito, no olvidando que la persona física debió actuar en nombre por cuenta y en beneficio de la persona jurídica. El legislador penal utiliza el concepto "sustraído" que deriva del verbo "sustraer", que, para efectos de entendimiento, es un concepto y una redacción confusa que no tiende a dar un significado concreto.

La Real Academia de la Lengua, lo define como "apartar, separar, extraer ${ }^{13}$ ", es un concepto que no da mayores detalles, apartarse de la acción de la justicia, pero, ¿en qué sentido? Y así los otros dos conceptos, no tienen un objetivo claro y definido, porque no determina como se va apartar y extraer del proceso penal. También establece este artículo que, si la persona jurídica deja de existir antes de que se dicte sentencia firme en el proceso instruido contra la persona jurídica, también responderá penalmente. Es notorio que las empresas por distintos motivos de un momento a otro dejan de existir, dejan de operar en el mercado que se desenvuelven. No cabe duda, que este modelo de responsabilidad penal, tiene una alta influencia en el Código Penal español. El Legislador hondureño utiliza una terminología amplia, al decir, "deje de existir" refiriéndose a la persona jurídica, es decir, que en cualquier circunstancia que la empresa deje de operar en el mercado mientras no exista una sentencia firme en el proceso penal, se podrá sancionar penalmente la empresa.

jurídicas en Latinoamérica y España. (217-240) Pamplona. Editorial Aranzadi SA.

13 https://dle.rae.es/sustraer?m=form consultada en fecha 13 julio 2020 
El legislador penal español fue un poco más concreto y fue un poco más allá, fue concreto en el sentido que, aunque la persona jurídica se transforme, se fusione en una nueva sociedad, o cuando una sociedad que existe absorbe a otras sociedades, o una sociedad mercantil se escinda en varias sociedades, no extingue la responsabilidad penal de estas; cuando se plantea que el legislador fue más allá, es que la responsabilidad penal, se trasladara a las persona jurídica fusionada, escindida, absorbida $^{14}$. Aquí hay un conflicto, que la persona jurídica nueva, escindida, fusionada o absorbida, no tiene dolo, no ha cometió delito, por lo tanto, no debe imputársele un delito que no ha cometido la persona jurídica, de esa manera se evita la responsabilidad objetiva a la nueva empresa.

Desde un punto de vista procesal, si a una persona jurídica se le deduce responsabilidad penal para salvaguardar los principios del Derecho Penal, de lege ferenda, como medida cautelar a la empresa, el juez debe imponer a la empresa la prohibición de llevar a cabo procesos de fusión, absorción o escisión, e inscribir estas medidas en el Registro Mercantil correspondiente para evitar que la persona jurídica ejecute lleve algún cambio que la haga evadir su responsabilidad penal. El hecho de deducir responsabilidad penal a la nueva persona jurídica que no ha cometido delito, únicamente tiene como objetivo, que esa responsabilidad penal no sea eludida ${ }^{15}$.

14 Cfr. Código Penal español: Art. 130.2: La transformación, fusión, absorción o escisión de una persona jurídica no extingue su responsabilidad penal, que se trasladara a la entidad o entidades en que se transforme, quede fusionada o absorbida y se extenderá a la entidad o entidades que resulten de la escisión. 15 Feijoo Sánchez, B. Tratado, Óp. Cit., pp.297-300.

\section{PERSONAS JURIDICAS QUE NO RESPONDEN PENALMENTE EN EL NUEVO CODIGO PENAL DE HONDURAS}

La Responsabilidad penal de las personas jurídicas, está pensada para las sociedades mercantiles de orden privado, aquellas que se encuentran registradas en el registro mercantil y operan con fines de lucro. En el artículo 103 del Decreto-Legislativo 1302017, establece que están exenta de recibir sanción penal las personas jurídicas como el Estado, las Organizaciones Internacionales de Derecho Público, aquellas entidades que posean atribuciones públicas de soberanía o administrativas, o también, se incluyen aquellas sociedades mercantiles estatales que lleven a cabo políticas públicas, o que estas sociedades mercantiles presten servicio de interés económico en general.

Es de recordar que para que se sancione una empresa con una pena, debe obrarse en beneficio de la empresa que compite con otras empresas en un mercado determinado, no se puede sancionar una empresa de Derecho Público, donde ese beneficio, el funcionario persona física no va a obtener beneficio alguno, pero eso no significa que no se podría castigar a las personas físicas, concretamente a los funcionarios que se encuentren al frente de esas empresas ${ }^{16}$, también debemos entender, que el órgano Judicial cuando hay delito sanciona penalmente a las personas, este poder del Estado pertenece al Estado mismo, y el Estado no puede sancionarse a sí mismo,

16 Dopico Gómez-Aller, J. (2018) "La Responsabilidad Penal de las Personas Jurídicas”. En De la Mata Barranco, N., Dopico Gómez-Aller., J. Lascuraín Sánchez, Nieto Martin, A. Derecho Penal Económico y de la Empresa. Óp. Cit. pp, (129-168). 
significa que si el poder sancionador impone una multa a una empresa jurídica estatal, el Estado se va a pagar a sí mismo la multa, y esto en cierto sentido carece de lógica, por ejemplo, en un caso hipotético, cuando se impone una multa a una empresa pública, ese dinero que se paga en concepto de multa se emite una orden de pago a la Tesorería General de la Republica por la condena y ese mismo dinero ingresaría a la misma Tesorería del Estado.

De igual manera no se va a sancionar aquellas empresas cuya facturación anual no superen los tres millones de lempiras. Hay un punto importante que señalar, que el trato que le da el Código Penal a las personas jurídicas, es un tratamiento privilegiado, donde se puede atenuar o suspender tal responsabilidad penal únicamente cumpliendo algunas directrices que da el Código, pero nunca se puede extinguir la misma. La responsabilidad penal de la empresa o de la persona jurídica, está pensada para aquellas estructuras empresariales complejas, de cierto tamaño donde el recurso humano tiende a ser una cantidad considerable de personas.

La punición de pequeñas empresas, también pueden sancionarse, factor importante es determinar como he planteado la economía, si la economía de un Estado es fuerte, robusta, dinámica, donde una empresa ponga en peligro el correcto funcionamiento del mercado, aun con todo el problema dogmático de la responsabilidad penal de las personas jurídicas, si me tocara decidir, diría que, si se sancione penalmente a las pequeñas empresas, pero si la economía es débil, lenta, contraída, no estaría de acuerdo a su sanción penal, pero si estaría de acuerdo a una sanción administrativa o civil a la empresa, o sancionar penalmente a las personas físicas de las pequeñas empresas, que sería la vía más correcta. Otro punto que determina el último párrafo del artículo 103 de este Código Penal, que determina, que, si una persona natural utiliza una persona jurídica para cometer delito, será sancionada la persona jurídica.

A fortiori, no estoy de acuerdo con lo anterior. Tal párrafo es claro, y dice, que una persona física utiliza una persona jurídica; esto da pie para entender, que una persona física utiliza como pantalla una persona jurídica para delinquir, donde esta persona jurídica en todo caso, bien se convierte en víctima de la persona natural que la administra, para que se concrete esta responsabilidad deben concurrir los requisitos del artículo 102 de este Código Penal, el punto discutible es, que la persona jurídica es un instrumento de la persona natural donde para la empresa no hay beneficio y si no hay beneficio no concurren las condiciones recogidas en el artículo precedente que es el 102 CP. Sobre este punto se han planteado algunos puntos referentes a no sancionar a las sociedades mercantiles pantalla, Prima facie, la persona jurídica no se beneficia de delito cometido por la persona natural, asimismo, la persona jurídica simplemente es un instrumento donde no existe dolo, no es un sujeto activo del delito ${ }^{17}$.

La responsabilidad penal de la empresa está preparada para aquellas empresas que operan legalmente en el mercado, no para aquellas empresas que operan al margen de la Ley y han sido creadas para delinquir. De acuerdo a este 17 Ibídem, pp. 135. 
artículo, no solo se va a sancionar penalmente a la empresa, también se sancionará a quienes gestionen a esas empresas, como a los administradores, fundadores o representantes que le saquen algún tipo de provecho a su cargo.

\section{SANCIONES PENALES A LAS PERSONAS JURIDICAS}

No es nada desconocido que este nuevo Código Penal contiene un nuevo sistema de penas, especialmente para personas físicas, y si esta responsabilidad penal de la persona jurídica no hubiese sido derogada, contendría también un avanzado sistema de penas. Como es sabido, se han planteado una serie de críticas sobre este último modelo de sanciones penales para las empresas, porque el mismo, rompe con el sistema tradicional de penas como ha sido la prisión. La pena de prisión está construida desde sus inicios pensando en la persona física, ahora modernamente a la hora de su imposición, busca la prevención de nuevos delitos, la resocialización del penado, se ha planteado que la persona jurídica no tiene la capacidad de comprender el carácter aflictivo de la pena, es decir, el carácter doloroso que representa la misma, al que algún profesor ha determinado que existe un trípode de incapacidades para determinar la responsabilidad pena de las personas jurídicas $\mathrm{y}$ entre esas incapacidades se encuentra el principio de personalidad de las penas, esto significa que la pena, como fin pierde su identidad resocializadora.

Asimismo, los delitos de empresa parten de la actuación delictiva de una persona física, significa que el delito sigue partiendo de que es ejecutado por una persona distinta a la persona jurídica, se extiende la norma penal a castigar aquella persona que no ha delinquido $^{18}$, y máxime todavía, que esta responsabilidad penal de la empresa que conlleva este Código, es un modelo de transferencia de responsabilidad penal, en vista de que no les exige a las empresas tener ex ante de la comisión del delito un modelo de gestión y prevención de delitos para ejecutar un debido control en la empresa.

Es obvio y notorio que una persona jurídica no puede encerrarse en una cárcel, sensu contrario, para ello, se han determinado una serie de penas que no son privativas de libertad para las personas jurídicas que son las que señala el artículo 104 del Código Penal Vigente. La pena aplicable a las personas jurídicas por excelencia es la pena de multa, todos los delitos de la parte especial contemplan la pena de multa para las personas jurídicas. Esta pena, el código la puede implementar en dos sentidos, en multas por cuotas o multa proporcional, ambas penas, están determinadas para la persona jurídica. Como ha determinado este Código, la multa por cuotas puede tener una extensión máxima de 2000 días, asimismo, sobre esta modalidad de sanción penal, la cuota de la multa puede variar, la cuota diaria puede tener un valor mínimo de L. 200.00 y un máximo de L. 50, 000.00 .

En este modelo el legislador le otorgo al Órgano Jurisdiccional una discrecionalidad para que sea él que determine la gravedad de delito, para determinar la gravedad del delito

18 Cuello Contreras, J., Mapelli Caffarena, B., (2015) Curso de Derecho Penal PG. Madrid. Tecnos. 
deberá atenderse a estudios periciales que debe presentar el ente acusador, ahí corresponderá con base en ese estudio más o menos que numero y cuál será la cantidad de dinero en cuotas a imponer a la empresa, para ello también el juzgador debe valorar la situación financiera, económica de la misma, deberá presentar estados de cuenta que deban reflejar los valores obtenidos del ilícito cometido, porque se ha dado una actividad delictiva, puede ser también que los beneficios obtenidos se oculten dando punto a otros delitos como falsificación de documentos, insolvencia, lo que si plantea algo de dificultad, es determinar aquellos beneficios que no son en dinero.

La segunda modalidad de sanción penal a la empresa es la multa proporcional, en vista de que de todo delito se obtiene un beneficio, claramente el código no puede imponer una multa concreta porque resulta que si taxativamente señala una multa específica, puede que resulte que el beneficio obtenido por la comisión delictiva sea mucho más alta que la multa que determina el Código, que también podría ser más baja, en ese sentido, la pena resultaría ineficaz, por tanto, la multa es proporcional al beneficio obtenido o que se pretendió obtener ${ }^{19}$. La multa proporcional se fija en atención al daño causado, igualmente que, en el punto anterior, el daño causado para valorarlo, se debe o podrá hacer mediante pericia, también podría determinarse mediante de volúmenes de ventas con respecto a cuanto ha sido el volumen de venta de años anteriores, con respecto al año en que se cometió el delito.

19 Cfr. Decreto 130-2017 Código Penal Art. 54: No obstante, lo dispuesto en el artículo anterior, cuando el presente Código así lo determine, la multa se establece en proporción al daño causado, al valor del objeto del delito o al beneficio obtenido o perseguido con el mismo.
El Código también plantea lo que denomina como penas potestativas, es decir, que, de acuerdo a su redacción, el Órgano Jurisdiccional estará facultado para disponer además de la imposición de la pena principal que determina el delito concreto, va a imponer otras penas, en tanto, un poco más duras que la pena de multa ${ }^{20}$.

El mismo Código Penal le impone al Juez una doble motivación en cuanto a la imposición de la pena principal de multa y la motivación sobre la pena potestativa es obligatoria, eso queda como una discrecionalidad del Órgano Jurisdiccional, para ello, el juzgador debe evaluar algunos puntos, si este Órgano Jurisdiccional entiende que solo con la imposición de la pena principal, no basta, porque entiende que podría continuar la actividad delictiva, en ese sentido, el juez puede imponer como pena potestativa el cese temporal de determinada actividad en la empresa, si en alguna sucursal de la empresa o en algún local de la misma se cometió un delito, pues se impondrá la pena de clausura de local y establecimiento donde se ejecutó el delito, entre otras.

Lo que, si hay algo inentendible, es acerca de la clasificación de las penas a las personas 20 Entre las penas adicionales que puede imponer el Juez, están las que señala el artículo 104.2: suspensión de actividades en las que se produjo el delito, 3) Clausura de los locales y establecimientos que se utilizaron para la realización del delito, por un plazo que no puede exceder de 5 años. 4) Prohibición de realizar en el futuro las actividades específicas en cuyo ejercicio se ha cometido, favorecido o encubierto el delito; 5) Inhabilitación para obtener subvenciones y ayudas públicas, para contratar con el sector público y para gozar de beneficios o incentivos fiscales o de la seguridad social por un plazo que no pueda exceder de 15 años. 6) Intervención judicial para salvaguardar los derechos de los trabajadores o de los acreedores por el tiempo que se estime necesario. 7) Disolución de la persona jurídica 
jurídicas, porque el Código no define si la pena de multa impuesta a la persona jurídica, es una pena grave, menos grave, o es una pena leve. Determina esta nueva normativa que la multa proporcional es una pena menos grave, es correcto preguntarse entonces, si una pena de multa proporcional de grandes proporciones podría considerarse como una pena menos grave.

Sobre la base de la teoría de la pena, ha evolucionado en el tiempo en distintos sentidos, pues se ha hablado de retribucionismo, de prevención, de resocialización, este último sería imposible determinarlo, ya que está construido para la persona humana, de igual manera, la retribución no cumple ningún objetivo en la sanción a la empresa, pero si es discutible la sanción penal a la empresa desde la prevención general y especial, prevención general en cuanto si se aplica una multa, pues es un mensaje para las otras empresas, y especial, en el sentido de que la imposición de una pena, llevara a la empresa a adoptar mecanismos efectivos de prevención, medidas de corrección para evitar delitos en el futuro ${ }^{21}$.

Un poco más concreto es el Prof. Dr. Feijoo Sánchez, al señalar que la multa a la empresa posee fines preventivos-generales, y las demás penas, cumplen objetivos preventivosespeciales ${ }^{22}$ para las personas físicas, no para la empresa, y siguiendo al mismo profesor anteriormente citado, las penas potestativas son de carácter prospectivos porque cumplen fines inocuizadores ${ }^{23}$ porque hay indicios de

21 Tesis Doctoral Francisco Estepa Domínguez, (2012) Universidad Internacional de Andalucía. La Responsabilidad penal de las personas jurídicas. pp. 35. Sevilla, España.

22 Feijoo Sánchez, B. Tratado, Óp. Cit., pp.280-281.

23 Ibídem, pp.282. reiteración delictiva que no basta aplicar una pena de multa.

\section{CIRCUNSTANCIAS QUE ATENUAN LA RESPONSABILIDAD PENAL DE LA PERSONA JURIDICA}

A la hora de deducir responsabilidad penal a la empresa se presenta una serie de privilegios, cuestión que no se presenta a la persona física a la hora de imponer una pena. Como puede entenderse, en este nuevo Código Penal, se presentan circunstancias modificativas de la responsabilidad penal, tanto para personas físicas $^{24}$ como para personas jurídicas, con respecto a estas últimas únicamente existen circunstancias atenuantes ${ }^{25}$, los cuales, el tratamiento a las empresas es bastante benévolo, el Código penal no hace mención a agravantes para las empresas para determinar la pena y no especifica si le son aplicables las agravantes genéricas del artículo 32 del CP.

Entre algunas atenuantes, tenemos que, "si la empresa confiesa a las autoridades la comisión del delito antes de que sus directivos y la empresa conozcan las investigaciones o la posible acusación que se dirigirá contra ella" podrá aplicarse esta atenuante, aquí podría plantearse algún problema o vale preguntarse algunas cuestiones, ¿cuándo se da cuenta la empresa que se dirige contra ella una investigación o una imputación penal?, Si la persona jurídica también tiene derechos procesales, ¿le abarcará la prohibición de autoincriminación? Asimismo, quién es la

24 Nuevo Código Penal de Honduras Decreto 130-2017, Véase articulo 31 y 32 contentivas de las circunstancias modificativas de la responsabilidad penal para personas físicas.

25 Ibídem, articulo 105 Circunstancias atenuantes para las personas jurídicas penalmente responsables. 
persona encargada de confesar el delito ${ }^{26}$; son algunas cuestiones que son valederas preguntarse.

En el mismo sentido, se determina como atenuante que, si la empresa no ha confesado el delito por cualquier circunstancia, una vez entendida que se está dirigiendo una investigación contra ella, la empresa colabora en la investigación de su delito, ¿pero de qué manera será su colaboración?, pues aportando las pruebas necesarias para el esclarecimiento de los hechos, pero esta aportación está condicionada a dos puntos: (i) que la aportación sea antes del juicio oral y público, y sobre todo, (ii) que esa aportación, sea de material probatorio nuevo, y totalmente decisivo para esclarecer los hechos. En un dado caso, la empresa no presenta sus pruebas decisivas, si viene la imputación, le da espacio a lo largo del proceso judicial analizar qué tan sólida es la acusación de la Fiscalía, si la defensa de la empresa entiende que puede haber una absolución por el órgano jurisdiccional no presenta esas pruebas decisivas que plantea la atenuante, si analiza que la fundamentación fáctica y jurídica del ente fiscal es sólida en la imputación penal, presenta tales pruebas decisivas para que se le otorgue la atenuante.

También, otra de las atenuantes, es que una vez cometido el delito y descubierto los hechos, "la empresa proceda a reparar o disminuir los daños causados por el delito”, pero esta reparación, debe haber sido antes de iniciarse el juicio oral, en Honduras para llegar

26 Gómez Martin, V., Valiente Iváñez, V. (2016) "Responsabilidad penal de las personas jurídicas. en: Corcoy Bidasolo, M, Gómez Martin, V., Manual de Derecho Penal, Económico, y de Empresa, PG y PE. (126-158) Valencia. Tirant Lo Blanch. al juicio oral hay que esperar un buen tiempo y ese margen de tiempo da espacio suficiente para indemnizar o aminorar los efectos del delito. Asimismo, el Código como ultima atenuante plantea, que una vez cometido el delito, y previo al juicio oral, la empresa debe incorporar "medidas eficaces para prevenir y descubrir los delitos que en el futuro pudieran cometerse con los medios o bajo la cobertura de la persona jurídica por sus representantes o administradores".

Prácticamente, el legislador le recomienda a la empresa que ex post a la comisión de delito instaure un programa de cumplimiento para que pueda optar a que se le atenué la pena; lo correcto hubiese sido que este Código Penal le exigiese a la empresa la aplicación de medidas de control interno ex ante de la comisión del delito, lo importante aquí, es que implementar tales medidas eficaces tengan efectos en la determinación de la pena, porque frente al juez hay que dar y acreditar un cambio de conducta empresarial implementando tales medidas; eso podría conllevar a la evitación de ser condenada la empresa a alguna pena potestativa $^{27}$ del articulo 104 en sus dos últimos párrafos de este nuevo Código Penal.

\section{SUSPENSION DEL PROCESO PENAL EN DELITOS COMETIDOS POR LAS PERSONAS JURIDICAS}

Llegamos al último tramo de la responsabilidad penal de la persona jurídica en el Código Penal, y es el artículo 106, el mismo presenta los requisitos de suspensión de los procedimientos por los delitos cometidos por la persona jurídica. No 27 Ibídem, 136. 
debemos olvidar que el delito de empresa, es cometido por una persona física, por cuenta, en nombre y beneficio de la persona jurídica, esos son los parámetros definitorios para deducir responsabilidad penal a la empresa. El legislador ha sido bastante comprensivo con la persona jurídica, podría generarse un problema de constitucionalidad en el plano de la igualdad, porque el modelo de imputación clásico para la persona física no es el mismo para la persona jurídica cuando se supone que ambas personas que van a responder por un delito están en las mismas condiciones penales y procesales y no debe haber privilegios para ninguna. Basta preguntarse si aplicamos el mismo modelo de responsabilidad penal de la empresa a la persona física; sin duda alguna, que hay una diferencia absolutamente enorme.

Este nuevo Código presenta una gama de medidas que están ampliamente vinculadas al Derecho Procesal Penal, habría que determinar aquí, en cual precepto jurídico del Código Procesal Penal vamos a encuadrar esta figura de la suspensión, la conciliación penal suspende el proceso que se somete algunos requisitos, igualmente, la suspensión condicional de la persecución penal del artículo 36 del CPP. Para que la persona jurídica pueda optar a la suspensión de proceso, debe ser la primera vez que comete un hecho delictivo en el marco de sus actividades empresariales.

Por otro lado, otro requisito que presenta el código, es que, "no exista peligro de reiteración delictiva”, para ello, el Órgano Jurisdiccional deberá hacer una valoración de la dinámica de los hechos, y de acuerdo a cuáles son la circunstancia de la persona jurídica. No obstante, es bastante difícil determinar esos puntos, por lo menos el que se refiere a la reiteración delictiva, no existe una teoría que determine y que mida el nivel de riesgo para valorar el peligro que una vez que se conceda la suspensión no va a volver a delinquir la empresa y sus administradores. Es muy raro que un delito no conlleve la responsabilidad civil del mismo, pero así lo plantea el artículo 106.3 del Código Penal, y ahí mismo señala, que previo a otorgarse la suspensión del proceso penal, la persona jurídica debe haber hecho efectivo el pago como indemnización por el daño causado.

Una cuestión importante que se suscita aquí es; a quien es que se le debe satisfacer el pago de la responsabilidad civil, si es al Estado, o a los competidores que operan en el mercado financiero, en el mercado de valores, o si es a ambos, no se especifica a quien hay que satisfacerle ese tipo de responsabilidad. En el mismo artículo anteriormente citado, en los incisos 4 y 5 se señalan dos requisitos para la suspensión, el primero, es que los representantes de la empresa colaboren con la investigación, y segundo, que la empresa reconozca su responsabilidad en los hechos. El termino colaboración es sumamente amplio, de cualquier manera, la empresa puede colaborar con las autoridades poniendo al personal de la empresa o a testigos a rendir información, presentar documentación de cualquier tipo, como ser estados de cuentas, correos electrónicos.

También, el hecho de que la persona jurídica reconozca su responsabilidad en los hechos delictivos, es un modo de colaborar con las investigaciones. Por cuestiones de espacio y de bastante similitud el inciso 4 y 5 del 
artículo 106 del Código Penal, los hubiesen dejado en un solo inciso. Porque entiendo, que, si los representantes de la persona jurídica colaboran con las investigaciones, esa colaboración puede ser el reconocimiento de la responsabilidad en los hechos, por eso veo innecesario el inciso 5.

De este último artículo citado en su inciso 4 , con el inciso 2 del artículo $105 \mathrm{CP}$, tiene bastante semejanza, el que atiende a que la persona jurídica colabore con las autoridades en la investigación de los hechos, con la diferencia que en el 105.2 CP, las pruebas fueran nuevas y decisivas, pero ahí, entre este último artículo $(105 \mathrm{CP})$ y el $106 \mathrm{CP}$, hay una gran diferencia, que en el primer artículo hay una condena a la persona jurídica solo que atenuada, y en el segundo artículo citado hay una suspensión del proceso penal en el cual no hay una condena, sino que se suspende el proceso en un plazo que lo determina el Órgano jurisdiccional que puede estar entre dos años mínimo y 5 años máximo, es una valoración que deberá hacer el Juez en el momento procesal oportuno tomando las características del hecho, la situación de la persona jurídica, etc., pero el hecho de la suspensión, el gobierno corporativo debe incorporar ciertos condicionamiento ordenados por el órgano jurisdiccional, los condicionamientos quedan a discrecionalidad del juez, el Juez debe hacer sus propias valoraciones sobre ello, entre los condicionamientos tenemos, "realización de cambios organizativos en la persona jurídica que minimicen el riesgo de reiteración delictiva", pues lógicamente que esto es entendible, que todo aquel empleado o administrador que se haya visto envuelto en el delito, pues tiene que ser cesado en su cargo, mantener las mismas personas da pie para entender que hay un alto riesgo de reiteración delictiva, pero esto de alguna manera se traslapa con lo que señala el inciso 4 de los condicionamientos que impone el Órgano Jurisdiccional a la persona jurídica, por ejemplo, se establece, que entre las directrices que ordena el Juez a la empresa, debe despedirse los ejecutivos responsables, esto con el objetivo de aminorar el riesgo de reiteración delictiva, como lo señalamos en otro apartado en este mismo análisis de artículo $106 \mathrm{CP}$, se hubiese suscrito un mismo considerando ambos condicionamientos.

En el mismo sentido, se plantean otra serie de condicionamientos que realiza el Juez una vez que concede la suspensión del procedimiento, como, por ejemplo, "implementar programas de prevención del delito" este programa podría incluir lo que se llama whistleblowing, que son canales de denuncia sobre cualquier ilicitud en la empresa, puede implementarse cualquier medida que tienda a la evitación del delito. Otro condicionamiento, es la "intervención judicial a la empresa" esto incluye auditorias o inspecciones y el costo de esto corre a cargo de la empresa.

En primer lugar, quien va a realizar la auditoria o la inspección, ¿el Estado?, o lo hará alguna big four, se sabe que una firma auditora no es barata y más tomando en cuenta la dimensión de delito y de los daños causados, y sila empresa está en un concurso de acreedores, y si la empresa está en bancarrota, surgen algunas cuestiones valederas que preguntarse como las anteriores, ¿le tocara pagar al Estado esas inspecciones o auditorias?, si se otorga la suspensión del proceso quiere decir que hubo 
una imputación penal a la empresa, previo hubo una investigación, esta intervención judicial estaría mejor planteada como una medida cautelar en vista de que las auditorias e inspecciones están más para sustentar el escrito de acusación penal y no para después que se otorga la suspensión del proceso.

Una vez otorgado el beneficio de suspensión, si la empresa comete otro delito, o incumple cualquiera de los condicionamientos impuestos, se ordenara por el órgano jurisdiccional la continuación del juicio, dejando sin lugar la suspensión, el plazo de suspensión es de 2 a 5 años, es una especie como periodo de prueba para determinar la conducta, la organización que adopta la empresa después de haberse acusado penalmente, una vez finalizado el plazo de la suspensión y si la empresa ha cumplido todos los condicionamiento del Órgano Jurisdiccional, se decretara la extinción de la acción penal y la empresa podrá operar normalmente.

\section{CONCLUSIONES}

- La aprobación de este nuevo Código Penal contemplando la responsabilidad penal de la persona jurídica, es una novedad en Honduras, no en otros países. No cabe duda que la influencia de este Código Penal, es de influencia española, con asesores españoles, tomando como borrador el Código Penal español. Estaría seguro que, si España no hubiese aprobado en el 2010 la RPPJ, Honduras tampoco lo hubiese tratado de hacer en este Código Penal.

- Si bien es cierto, la economía hondureña no es tan dinámica, ni sólida para mantener en vigencia la responsabilidad penal de la empresa, puede ser que en algún momento lo sea y si existe una dogmática consecuente con ello, pero por ahora no, es por lo primero que no ha existido presión internacional para que se apruebe tal responsabilidad que en algún momento puede haber presión de organismos internacionales, como paso con Chile con la OCDE.

- Siempre el debate se va a mantener que la persona jurídica no delinque, como dice el Dr. Feijoo Sánchez, es un debate desenfocado, porque la teoría del delito como eje central de la dogmática penal opera desde sus inicios sobre sujetos de forma individualizada, sobre el propio sujeto físico, de carne y hueso; y como señala el Prof. Dr. Dr. h. c. mult. Winfried Hassemer, que, si el Derecho Penal va sobre sujetos individualizados, el concepto de imputación penal no se debe dirigir contra personas colectivas, porque el ataque penal se dirige al cuerpo (persona física) ya sea como pena privativa de libertad o como prisión preventiva ${ }^{28}$.

- A mi modo de ver, esta responsabilidad penal de las sociedades mercantiles que se analiza aquí, es como un parcho de la responsabilidad penal de la empresa del código Penal español, en vista de se supone que los asesores (aunque seguramente lo recomendaron a la Comisión redactora del CP ) de este código deben recomendar con base en las experiencias en sus países, que puntos han sido buenos y que puntos 28 Hassemer, W. (1999) Persona, Mundo y Responsabilidad, Bases para una teoría de la imputación en Derecho Penal. Bogotá. Edit. Temis. 
han sido malos para que su asesorado no caiga en los mismos errores, por ejemplo, el artículo 31 bis 2.a) del código penal español especifica las exenciones de responsabilidad penal a la empresa y una de ellas es que se haya adoptado antes de cometerse el delito modelos de organización y gestión donde se incluyen controles de la actividad empresarial a lo interno de la empresa ${ }^{29}$, en este código, no se exige los modelos de prevención previo a la comisión del delito, y se exigirá para suspender el procedimiento penal a la empresa que adopte programas de prevención; el código penal no dice si estos programas deben ser idóneos, porque entre modelos de prevención idóneos y modelos de prevención hay una enorme diferencia

- Esta responsabilidad actualmente al 31 de julio 2020 está vigente, en vista de que el Código Penal entro en vigencia el 25 de junio 2020 y a esta fecha no hay un decreto que la derogue en su totalidad y no hay una publicación en el Diario Oficial La Gaceta donde se publique su derogatoria.

\section{AGRADECIMIENTO}

Agradezco la invitación a escribir este pequeño aporte a los Profesores de Derecho Penal, Abogado Rafael López Murcia, y al Abogado Jacobo Calix.

29 Cfr. código penal español: Si el delito fuere cometido por las personas indicadas en la letra a del apartado anterior, la persona jurídica quedara exenta de responsabilidad si se cumplen con las siguientes condiciones: $1^{\text {a }}$ el órgano de administración ha adoptado y ejecutado con eficacia, antes de la comisión del delito modelos de organización y gestión que incluyen las medidas de vigilancia y control idóneas para prevenir delitos de la misma naturaleza o para reducir de forma significativa el riesgo de su comisión.

\section{BIBLIOGRAFIA}

Bacigalupo, S. (2002) La responsabilidad penal de las personas jurídicas: Un problema del sujeto del Derecho penal. En: Mir Puig, S., Modolell Gonzales, J.L., Gallego Soler, J-I., Bello Rengifo, C.S., Estudios de Derecho Penal Económico (152-182) Venezuela. Livrosca.

Boletín Oficial del Estado. https://www.boe. es/buscar/act.php?id=BOE-A-2015-3439.

Código Penal español.

Código Penal de Honduras: DecretoLegislativo 130-2017.

Cuello Contreras, J., Mapelli Caffarena, B., (2015) Curso de Derecho Penal PG. Madrid. Tecnos.

Dopico Gómez-Aller, J. (2018) "La Responsabilidad Penal de las Personas Jurídicas". En De la Mata Barranco, N., Dopico Gómez-Aller., J. Lascuraín Sánchez, Nieto Martin, A. Derecho Penal Económico y de la Empresa. (129-168) Madrid. Dykinson.

Feijoo Sánchez, B. (2015) "Los Requisitos del Artículo 31 bis 1". En Bajo Fernández, M, Feijoo Sánchez, B.J., Gómez-Jara, C. Tratado de Responsabilidad Penal de las Persona Jurídica (75-88) Civitas. Navarra.

Gómez Martin, V., Valiente Iváñez, V. (2016) "Responsabilidad penal de las personas jurídicas. en: Corcoy Bidasolo, M, Gómez 
Martin, V., Manual de Derecho Penal, Económico, y de Empresa, PG y PE. (126158) Valencia. Tirant Lo Blanch.

Hassemer, W. (1999) Persona, Mundo y Responsabilidad, Bases para una teoría de la imputación en Derecho Penal. Bogotá. Edit. Temis. https://dle.rae.es/sustraer?m=form consultada en fecha 13 julio 2020.

Paniagua, R. (2017). Fundamentos de la Responsabilidad Penal de la Empresa como nuevo sujeto activo del delito. Revista de Derecho, Volumen 38, No 1, 20, 15-24.

Pérez Manzano, M. (2019) "Principios del Derecho Penal (III)". En Manual de Introducción al Derecho Penal, (91-117) Madrid, BOE.

Ragués i Vallés, R. (2018) “Delito y Empresa”. En Ragués i Vallés, R, Robles Planas (dirs), R. La Imputación Subjetiva en los Delitos Económicos y en la Criminalidad de Empresa. (93-118) Barcelona. Atelier.

Silva Sánchez, J.M. (2013) La responsabilidad penal de las personas jurídicas en Derecho Español. En Silva Sánchez J.M. Dir., Montaner Fernández, R., Coord. "Criminalidad de Empresas y Compliance" Prevención y reacciones corporativas. (1542) Barcelona. Atelier.

Tesis Doctoral Francisco Estepa Domínguez, (2012) Universidad Internacional de Andalucía. La Responsabilidad penal de las personas jurídicas. pp. 35. Sevilla, España.
Responsabilidad Criminal de las Personas Jurídicas en el Derecho Español. (Análisis de la cuestión tras la reforma operada por la LO 1/2015, de 30 de marzo) En Zugaldía Espinar, J.M., Marín de Espinosa Ceballos E.B., La Responsabilidad Criminal de las personas jurídicas en Latinoamérica y España. (217-240) Pamplona. Editorial Aranzadi SA. 